\title{
LASERS IN PROSTHODONTICS- A REVIEW.
}

Sandesh Gosawi, Sanajay Kumar, Rohit Lakhyani, Shraddanand Bacha, Shivaraj Wangadargi
1. Professor \& HOD, Department of Prosthodontics, College of Dental Sciences, Amargadh, Gujarat, India.
2. Senior Lecturer, Department of Prosthodontics, College of Dental Sciences, Amargadh, Gujarat, India.
3. Senior Lecturer, Department of Prosthodontics, College of Dental Sciences, Amargadh, Gujarat, India.
4. Senior Lecturer, Department of Prosthodontics, College of Dental Sciences, Amargadh, Gujarat, India.
5. Reader, Department of Prosthodontics, College of Dental Sciences, Amargadh, Gujarat, India.

\section{CORRESPONDING AUTHOR}

Dr. Sanajay Kumar, Sr. Lecturer,

Department of Prosthodontics,

College of Dental Sciences, Amargadh,

Gujarat State, India.

E-mail: drsanajay@in.com,

Ph: 009107359270096.

ABSTRACT: Since the development of the ruby laser by Maiman in 1960, a variety of studies on the potential applications of lasers in dentistry have been conducted. Many applications like computer aided design and rapid prototyping technology, and study of occlusion in complete dentures using three-dimensional laser scanner have been developed. Its applications range from fixed Prosthodontics to treatment of dentinal hypersensitivity to surface treatment of base metal alloys. Today it even extends to the fields of dental implantology and maxillofacial Prosthodontics. This article reviews and summarises various studies of the laser applications in Prosthodontics.

KEY WORDS: LASER, complete denture, CAD/CAM, Impression, Dentinal hypersensitivity, Alloys, Crown, Preparation, Welding, Dental implants, maxillofacial prosthesis.

INTRODUCTION: Light is an integral part of our life. The early 20th century saw one of the greatest inventions in science \& technology, in that LASERS (Light Amplification by Stimulated Emission of Radiation) which later went on to became a gift to health sciences. A laser is an instrument that produces a very narrow, intense beam of light energy (electromagnetic radiation) through a process called stimulated emission. Albert Einstein is usually credited for the development of the laser theory. He was the first one to coin the term "Stimulated Emission" in his publication "Zur Quantentheorie der Strahlung", published in 1917 in the "Physikalische Zeitschrift"1.

The use of lasers for treatment has become a common phenomenon in the medical field. Theodore Harold Maiman is generally given credit for building the first working ruby laser and operating it for the first time on May 16, 1960 at the Hughes Research Laboratory in Malibu, California. MASER a microwave amplifier by Charles H.Townes, P.Gordon et al became the basic principle for laser pumping. This set the stage for a "snowball effect" which would lead to the development of many laser systems, which we utilize in healthcare today. The application of a laser to dental tissue was reported by Stern and Sognnaes and Goldman et al. in 1964, describing the effects of ruby laser on enamel and dentine with a disappointing result. However, with the recent advances and developments of wide range of laser wavelengths and different delivery systems, researchers suggest that lasers could be applied for the dental treatments. ${ }^{1}$

Currently, numerous laser systems are available for dental use. Neodymium-doped: Yittrium-Aluminium-Garnet (Nd: YAG), carbon dioxide (CO2) and semiconductor diode lasers 
have already been approved by the United States Food and Drug Administration for soft tissue treatment in oral cavity. The Erbium doped: Yttrium-Aluminium-Garnet (Er: YAG) laser was approved in 1997 for hard tissue treatment in dentistry ${ }^{2}$.

BACKGROUND KNOWLEDGE: The basic components of a laser are straightforward and are always similar regardless of the type of equipment. They include an active lasing medium within an optical cavity (resonator) and a pumping source (energy source). The optical cavity consists of two mirrors placed on either side of the laser medium. Due to this arrangement, photons resulting from the stimulated emission will form a continuous avalanche process. As long as the pumping energy maintains the population inversion in the active medium, more stimulated photons are created thus producing energy. The energy is absorbed and emitted in the resonator and with the aid of mirrors, is reflected and resonates within this chamber, and ultimately produces laser light. Because one of the mirrors is partially transmissive, some of the laser energy escapes at one end of the device into a delivery system .Consequently; a laser is just a source to generate a high energetic beam of light, which is monochromatic, collimated and coherent. In medical is the photo thermal effect in the range of $\mathrm{m} s e c$ to sec of irradiation time. The light energy is converted into thermal energy, which is locally cooled by water that irrigates the irradiated and surrounding tissue. As the temperature increases at the surgical site, the tissues can be warmed up to $\left(37-50^{\circ} \mathrm{C}\right)$, coagulated $\left(60-70^{\circ} \mathrm{C}\right)$, welded $\left(70-90^{\circ} \mathrm{C}\right)$, and vaporized $\left(100-150^{\circ} \mathrm{C}\right)$. If the laser energy continues to be absorbed by the tissue, carbonization occurs $\left(>200^{\circ} \mathrm{C}\right)$ and with it the possibility of significant tissue damage. Consequently, both target and surrounding tissues can be subjected to these harmful effects. ${ }^{3,4}$

\section{LASERS USED IN PROSTHODONTICS:}

\section{I) COMPLETE DENTURE PROSTHODONTICS:}

i) Prototyping and CAD/CAM (Computer Aided Design and Computer Aided Manufacturing) technology.

ii) Analysis of occlusion by CAD/CAM.

iii) Analysis of accuracy of impression by laser scanner.

\section{II) FIXED PARTIAL DENTURE:}

i) Tissue management.

ii) To treat dentinal hypersensitivity.

iii) Pretreatment of non-precious alloys.

iv)Crown preparation?

\section{III) REMOVABLE PARTIAL DENTURE:}

Laser welding.

\section{IV) IMPLANT DENTISTRY:}

i) Soft tissue surgery.

ii) Implant surface debridement.

iii) Implant surface treatment. 
V) MAXILLOFACIAL PROSTHODONTICS:

i) Sintering with CAD/CAM technology.

I) COMPLETE DENTURE PROSTHODONTICS:

I) PROTOTYPING AND CAD/CAM TECHNOLOGY: The term rapid prototyping (RP) refers to a class of technologies that can automatically construct physical models from Computer-Aided Design (CAD) data. These "three dimensional printers" allow designers to quickly create tangible prototypes of their designs, rather than just two-dimensional pictures. Such models have numerous data.

In addition to prototypes, RP techniques can also be used to make tooling (referred to as rapid tooling) and even production-quality parts (rapid manufacturing).A software package slices the CAD model in to a number of thin $($ eg. $0.1 \mathrm{~mm})$ layers, which are then built up one atop another. Rapid prototyping is an additive process, combining layers of paper, wax, or plastic to create a solid object.

In contrast, most machining processes (milling, drilling, grinding, etc.) are "subtractive" processes that remove material from a solid block. RP's additive nature allows it to create objects with complicated internal features that cannot be manufactured by other means. 5,6

LASER RAPID FORMING OF A COMPLETE TITANIUM DENTURE BASE PLATE: ${ }^{7}$ This technique uses the combination of the CAD/CAM and LRF (Laser Rapid Forming) methods for forming the titanium plate of a complete denture. Laser scanner, reverse engineering software, and standard triangulation language (STL) formatted denture base plate and sliced into a sequence of numerical controlled codes.

The denture plate will be built layer-by-layer, on the LRF system.

After the traditional finishing techniques, this denture plate will be acceptable for use in patients.

II) STUDY OF COMPLETE DENTURE OCCLUSION USING BY THREE-DIMENSIONAL TECHNIQUE: ${ }^{8}$ After fabrication of new dentures the occlusion can be examined and studied with the help of laser scanner technique and three-dimensional reconstruction. The relationship between the parameters of balanced occlusion can also be analyzed.

III) ANALYSIS OF ACCURACY OF IMPRESSION BY LASER SCANNER: ${ }^{9}$ Several studies have made comparisons in the dimensional accuracy of different elastomeric impression materials. Most have used two dimensional measuring devices, which neglect to account for the dimensional changes that exist along a three-dimensional surface.

The scanning laser three-dimensional (3D) digitizer can delineate $\mathrm{x}, \mathrm{y}$, and $\mathrm{z}$ coordinates from a specimen without actually contacting the surface. The digitizer automatically tracks coordinates with precision and stores data as the number of points on a surface with a resolution of $130 \mathrm{~mm}$ at $100 \mathrm{~mm}$. These exacting features suggest that the laser digitizer might accurately and reliably measure the dimensions of dental impression materials while avoiding subjective errors.

The image is built up and landmarks identified which allow superimposition of the images and so enable the differences between two similar images to be calculated.

The 3D laser captures complex 3D texture-mapped models and they are exported into a 3D (Scan Surf) software application where it is built and triangulated into a 3D meshwork image 
of the object. The scanning process is accomplished within a minute whereas the software analysis takes much longer. The software superimposes the two objects by either registering landmarks or by registering as iterative closest point (ICP). This finds an optimal fit between the two surfaces and in effect acts as a reference area. Once superimposed, the difference of the two surfaces is calculated as the shortest distance of each point on one object surface from a second object surface, within a range of $0.5 \mathrm{~mm}$.

Three-dimensional digitizers will eventually become less expensive, require less maintenance, track faster, and be available with more standardized software.

\section{FIXED PARTIAL DENTURE:}

\section{I) TISSUE MANAGEMENT:}

Crown lengthening: ${ }^{4}$ This is a procedure when inadequate crown height is present for crown restoration an adequate crown height is created by removing required gingival soft tissue.

With the help of the lasers soft tissue crown lengthening can be done without raising a flap. By its thermal effect the laser seals vascular and lymphatic vessels at the same time it vaporize the excess gingival tissue.

Since no flap was required for this surgery, sutures were not necessary and the wound healed by secondary intention.

\section{ADVANTAGES:}

Increased coagulation that yields a dry surgical field and better visualization.

Tissue surface sterilization and therefore, reduction in bacteremia.

Decreased swelling, edema of target tissue.

Decreased pain, and in some cases no need of anesthesia while surgery.

Faster healing response and increased patient acceptance.

Less chair-side time.

\section{II) TO TREAT DENTINAL HYPERSENSITIVITY:10,11}

There are many theories to describe the mechanism of hypersensitivity, but all conclude that open dentinal tubules are the path of stimuli to elicit response.

The first laser use for the treatment of dentine hypersensitivity was reported by Matsumoto et al (1985) using Nd: YAG laser. Many of the lasers investigated can induce significant thermal effects, if laser parameters are inadequately controlled, giving rise to concerns regarding thermal damage to temperature sensitive pulpal tissue.

MECHANISM OF ACTION OF LASERS IN TREATING DENTINAL HYPERSENSITIVITY: The precise mechanism of the ablation of hard tissues with the laser remains unclear. One theory suggested that when laser interacts with the hard tissue it is absorbed by the water and hydroxyapatite. The laser heats the water causing it to become steam. This expansion during the change of state of water causes cracking of the tissue. As the steam expands it also forces the cracked material away from the ablation zone. Because this is a very rapid action, it is explosive (micro explosion) in nature. The lasers used for the treatment of the dentinal hypersensitivity are divided in to two groups.

HE-NE LASER: The first use of this laser for the treatment of dentine hypersensitivity was reported by Senda et al. (1985).Irradiation modes were two types: pulsed (5 Hz only) and 
continuous wave (CW) mode. Treatment effectively ranged from 5.2 to $100 \%$. The mechanism involved is mostly unknown, but according to physiological experiments it increases the action potential of related nerve fiber. Its action will be long lasting.

GAALAS LASER: The first use of this laser for the treatment of dentine hypersensitivity was reported by Matsumoto et al.(1985).An output power of $30 \mathrm{~mW}$ was used for the treatment. Irradiation mode was $\mathrm{CW}$, and irradiation time ranged from 0.5 to $3 \mathrm{~min}$. Treatment effectiveness ranged from 85 to $100 \%$. The mechanism of action involved is blocking the depolarization of C-fiber afferents. (Wakabayashi et al.1992-1993).

ND: YAG LASER: The first use of this laser for the treatment of dentine hypersensitivity was reported by Matsumoto et al. (1985).The output power used may vary but 1-2 W is sufficient most commonly. The use of black ink as absorption enhancer is recommended when using $\mathrm{Nd}$ : YAG laser to prevent deep penetration of the laser beam through the enamel and dentin and excessive effects on pulp. ${ }^{12}$

$\mathbf{C O}_{2}$ LASER: The first use of this laser for the treatment of dentine hypersensitivity was reported by Moritz et al.(1996).Effect of this laser on dentinal hypersensitivity treatment is due to the occlusion or narrowing of dentinal tubules. This laser irradiation may also cause dentinal desiccation, yielding temporary clinical relief of dentinal hypersensitivity (Fayad et al.1996). $\mathrm{CO}_{2}$ laser with $1 \mathrm{~W}$ for 5-10 s duration could treat dentin hypersensitivity without adversely affecting the pulp.13

ER: YAG LASER: This laser came up after all the above to avoid some of the disadvantages they have. These lasers are basically advantageous than above in the nature that these produce very less heat while application due to better absorption by water and hydroxyapatite. Desensitizing effects of this laser are effective and long lasting compared to above lasers at $80 \mathrm{mj}$ and $3 \mathrm{~Hz}$ output. Its desensitizing affects attributed to the deposition of insoluble salts in the exposed dentinal tubules. ${ }^{14,15}$

ER: CR: YSGG LASER: This is a recent laser tool using in dentistry for variety of purposes. The mechanism of dentin removal as explained above for other erbium laser is by "thermo mechanical process" in which the emission laser light is absorbed by the water within the hydroxyapatite of a dental hard tissue. The water is then heated and evaporated, resulting in a high pressure of steam that causes a micro explosion of tooth tissue below the melting point of tooth tissue (approximately 1,200º ). Cumhur Sipahi, Nukhet Berk and Julide Ozen 2006 showed that long time-low potency (LT/LP) Er, Cr: YSGG lasers at $0.5 \mathrm{~W}$ potency for 30s produce required dentinal tubule closure to treat dentinal hypersensitivity. ${ }^{16,17}$

III) CROWN PREPARATION: ${ }^{18}$ Crown preparation with lasers a debated topic still. There are no conclusive studies yet showed the use of lasers for crown preparation purposes. But still some commercial companies say that they can be used. The following is the details what these companies say:

Er, Cr: YSGG laser is used most commonly now.

It uses hydrokinetic technology (laser-energized water to cut or ablate soft and hard tissue).

Journal of Evolution of Medical and Dental Sciences/Volume1/ Issue4/October - 2012 Page 628 
Because of this mechanism local anesthesia is not required in many cases, making this more comfortable procedure for the patient, and of course, saving time and anesthetic use by the patient.

The laser hand piece resembles a high-speed

hand piece but with fiber-optic tips instead of a bur, which directs the laser energy at a focal point approximately 1-2 $\mathrm{mm}$ from the tissue surface.

The crown preparation should be started on maximum setting for cutting enamel (6 $\mathrm{W}, 90 \%$ air, $75 \%$ water),started with a defocused mode for 30 seconds to $1 \mathrm{~min}$ for anesthesia of tooth.

While placing the gingival margin setting will be reduced $1.25 \mathrm{~W}, 50 \%$ air, $40 \%$ water to control the cutting tip, for the purpose of accuracy.

To finish with the interproximal, buccal, lingual/palatal reduction cuts will be performed with the dentin settings $4 \mathrm{~W}, 65 \%$ air, $55 \%$ water.

The laser has to be reset at $2.25 \mathrm{~W}, 65 \%$ air, $55 \%$ water to finish the buccal cusp overlay, and the final Margi nation of the proximal and lingual surfaces.

\section{ADVANTAGES:}

For vital crown preparation no need of local anesthesia, as laser causes temporary paresthasia of nerve endings.

Procedure is accurate and faster than the conventional method.

\section{DISADVANTAGES:}

Trained dentist required the particular use.

\section{REMOVABLE PARTIAL DENTURES: ${ }^{19}$ Laser welding:}

One of the modern methods of removable partial dentures defect repairs uses the pulsed laser with relative low average out power. This is known as a precise and rapid joining method, but its success depends on the control of many parameters.

Eg: For Co-Cr alloy frameworks:

The welding parameters were determined for each defect type and working step (fixing, joining, filling, planning).Adequate combination of pulse energy (6-14 J), pulse duration (10-20 $\mathrm{ms}$ ) and peak power (600-900 W) depending on the working stage improves the success of the welding procedure.

\section{IMPLANT DENTISTRY:20,21}

FOR STERILIZATION OF SOCKET: In immediate implant dentistry after extraction of tooth, without any infection, socket can be sterilized immediately without any pain.

IN CASE OF PERI- IMPLANTITIS: Since the laser does not transmit damaging heat, it can be utilized to vaporize any granulation tissue as well as clean the implant surface in periimplantitis cases. This procedure eliminated the acute state of peri-implantitis, resulting in positive GTR, and allowing the patient extended use of the implant.

TO DEBRIDE THE IMPLANT SURFACE: Miller Robert has shown that treatment of the contaminated implant surface by mechanical and chemotherapeutic means has met with mixed success. Development of a laser system operating at $2780 \mathrm{~nm}$ and using an ablative 
hydrokinetic process offers the possibility for more efficient decontamination and debridement. Laser ablation using the Er: Cr: YSGG laser is highly efficient at removing potential contaminants on the roughened implant surface while demonstrating no effects on the titanium substrate.

V.IN MAXILLOFACIAL PROSTHESIS: ${ }^{22}$ New advances in rapid prototyping technologies have demonstrated significant advantages compared to more conventional techniques for fabricating facial prosthesis. The use of selective laser sintering technology is an alternative approach for fabricating a wax pattern of maxillofacial prosthesis. This new approach can generate the wax pattern directly and reduce labor-intensive laboratory procedures.

SLS (SELECTIVE LASER SINTERING): The SLS (Selective Laser Sintering) is a method of computer aided designing using mainly the laser. In this method models are generated directly from 3-D computer data then converted to STL files, which are then sliced in to thin layers (typically about $0.1 \mathrm{~mm} / 0.004$ inches) using the associated computer software. The laser sintering machine produces the models on a removable platform by applying incremental layers of the pattern material. For each layer, the machine lays down a film of powdered material with an accurate required thickness, again a fresh film of powder is laid down, and the next layer is melted with exposure to the laser source. This process continues, layer by layer, until the pattern is completed.

ADVANTAGES:

Manufacturer time is reduced.

More precision can be achieved.

\section{REFERENCES}

1. T.H.Maiman. 1960.Stimulated optical radiation in ruby. NATURE; Aug 6.

2. Ishikawa I, Aoki A, Takasaki AA. 2004. Potential applications of Erbium:YAG laser in periodontics. J Periodontal Res. Aug;39(4):275-85.

3. A.J.Welch, Jorge H.Torres, Wai-Fung Cheong. 1989. Laser physics and Lasertissue interaction. Texas heart institute journal; 16:141-9.

4. Dr.AndrE Chartand. April 2005.Integrating laser dentistry in to aesthetic dentistry. Cosmetic dentistry, Oral health.

5. Richard J.Thomas US. Dec 26, 2006. Method for automatically creating a denture using laser altimetry to create a digital 3-D oral cavity model and using a digital internet connection to a rapid steriolethographic modeling machine. United States patent US 7,153,135 B1.

6. Sun YC, Lu PJ, Wang Y et al. 2007.Research and development of computer aided and rapid prototyping technology for complete dentures. Chinese Journal of Stomatology; 42:6:324-9.

7. Wu J, Gao B, Tan $\mathrm{H}$ et al. 2008 Aug 21. A feasibility study on laser rapid forming of a complete titanium denture base plate. Lasers Med Sci.

8. E.Y.Lu, F.Q.Zhang, X.J.Chen et al. June 28-July1, 2006. A study of complete denture e occlusion using by three-dimensional technique. IADR exhibition.

9. Sinal Shah, Geeta Sundaram, David Bartlett et al. 2004.The accuracy of a 3D laser scanner using superimposition software to assess the accuracy of impression techniques. Journal of Dentistry; 32:653-658.

10. Kimura Y, Wilder-Smith P, Yonaga K et al. 2000. Treatment of dentine hypersensitivity by lasers: a review Clin Periodontal; 27:715-721. 
11. Cumhur Sipahi, Nukhet Berk, Julide Ozen et al. 2006.Tubule-occluding effect of desensitizing laser treatment on prepared dentin surfaces: An environmental SEM study. Int J Prosthodont;19:37-39.

12. Bor-Shiun Lee, Chun-Wei Chang, Weng-Pin Chen et al. 2005. In vitro study of dentin hypersensitivity treated by Nd: YAP laser and bioglass. Dental Materials; 21:511-519.

13. Wan-Hang Lan, Kau-Wu Chen, Jiiang-Huei Jeng et al. 2000.A comparison of the morphological changes after $\mathrm{Nd}$ : YAG and $\mathrm{CO}_{2}$ laser irradiation of dentin surfaces. Journal of Endodontics; 26:8:450-453.

14. Oberhofer 0, Sculean A. 2008.Er: YAG laser and desensitizing effects on dentin and dental cervices. J Oral Laser Application; 3.

15. Yuki NISHIMOTO, Masayayuki OTSUKI, Monica YAMUTI et al. 2008. Effect of pulse duration of Er: YAG laser on dentin ablation. Dental Materials Journal; 27:3:433-439.

16. Piyanart Ekworapoj, Sharanbir K.Sidhu, and John F.McCabe. 2007. Effect of different power parameters of Er: Cr: YSGG laser on human dentine. Lasers Med Sci; 22:175-182.

17. Emre Altundasar, Bahar Ozcelik, Zafer C.Cehreli et al. 2006.Ultra morphological and histochemical changes after Er: Cr: YSGG laser irradiation and two different irradiation regimens .JOE; 32:5:465-468.

18. Dr.Rosh nash. Oct 2002.Crown and veneer preparation using the Er, Cr:YSGG Waterlase $^{\mathrm{TM}}$ hard and soft tissue laser. Cotemporary esthetics and restorative practice,80-85.

19. Liliana sandu,V.Birdeanu. 2006. Laser welding procedures applied to removable partial denes framework repairs.Europian cells and materials.11 (2):29.

20. Stefan stubinger, Frank homann. 2008. Effect of Er: YAG, CO2 and diode laser irradiation on surface properties of zirconia endosseous dental implants. Laser in surgery and medicine. 40(3):223-228.

21. Miller, Robert J. 2004.Treatment of the contaminated implant surface using the Er, Cr;YSGG laser. Implant dentistry. 13(2):165-170.

22. Guofeng $\mathrm{Wu}$, Bing Zhou. 2008. Selective laser sintering technology for customized fabrication of facial prostheses. J Prosthet Dent; 100:56-60.

Fig I Nd: YAG laser emission.

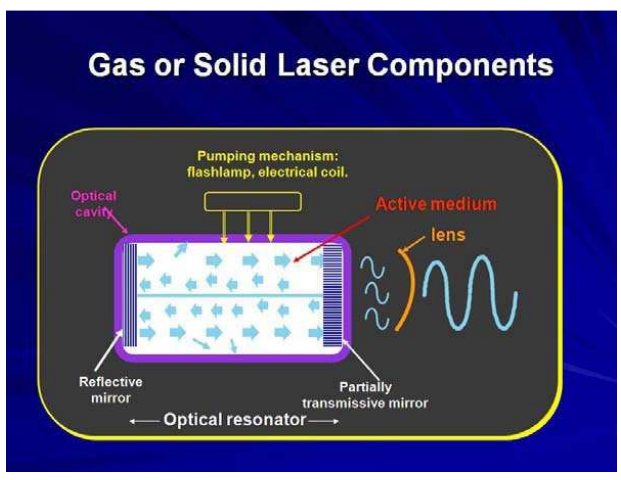

Journal of Evolution of Medical and Dental Sciences/Volume1/ Issue4/October - 2012 Page 631 


\section{REVIEW ARTICLE}

Fig II Images captured by the scanner of the teeth.

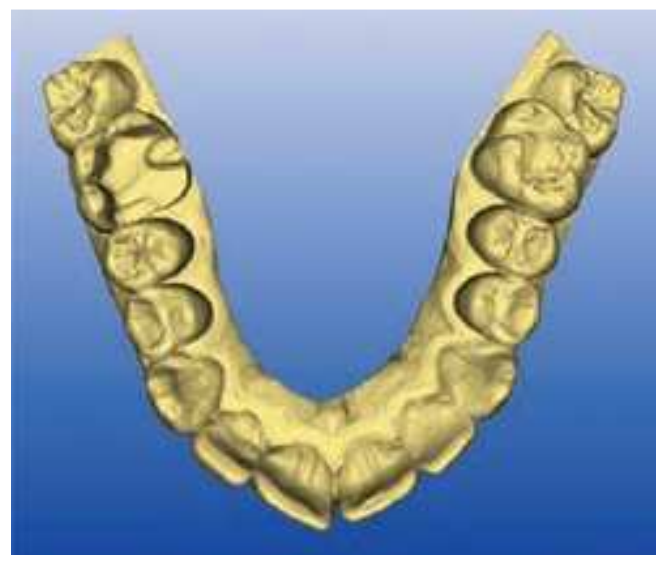

Fig III

a.Pre-operative.

b.Laser tip.

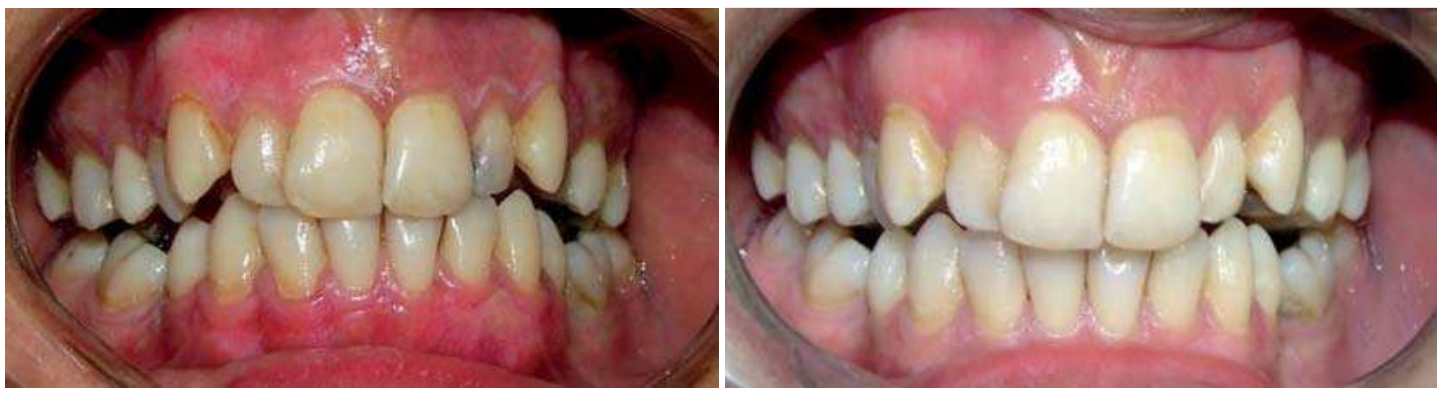

c. Post-operative

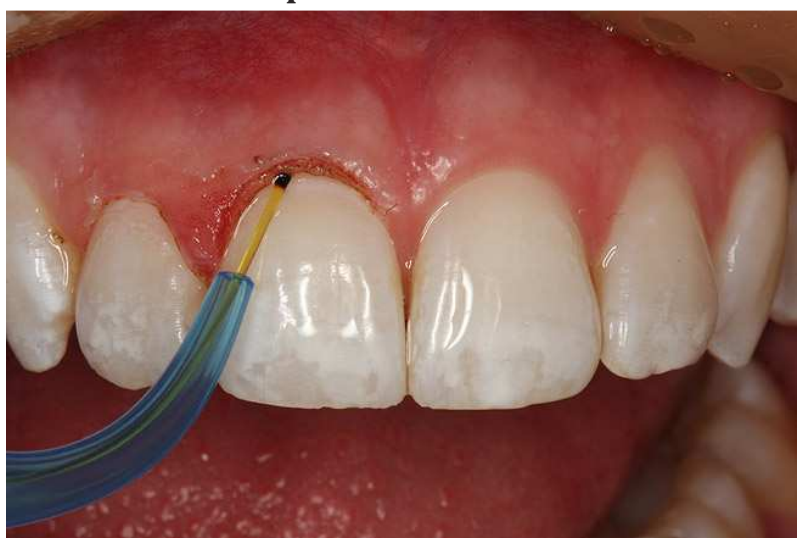




\section{REVIEW ARTICLE}

Fig IV a. SEM photograph of dentin Er;YAG laser.

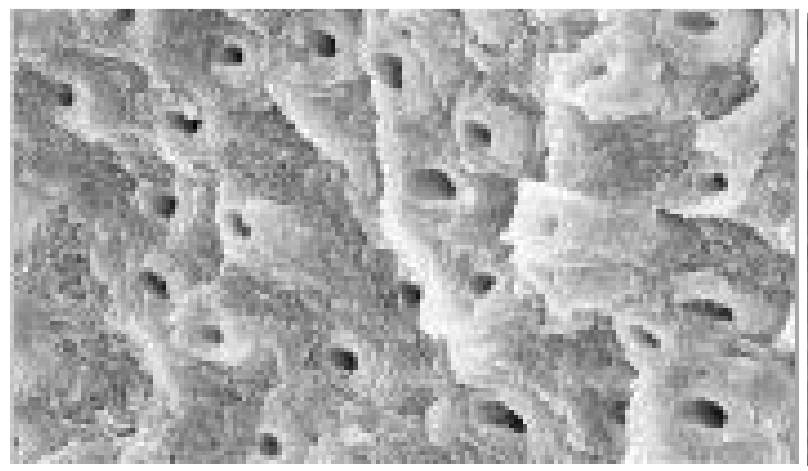

b.Plume from dentin ablation with the ablated with Er; YAG laser.

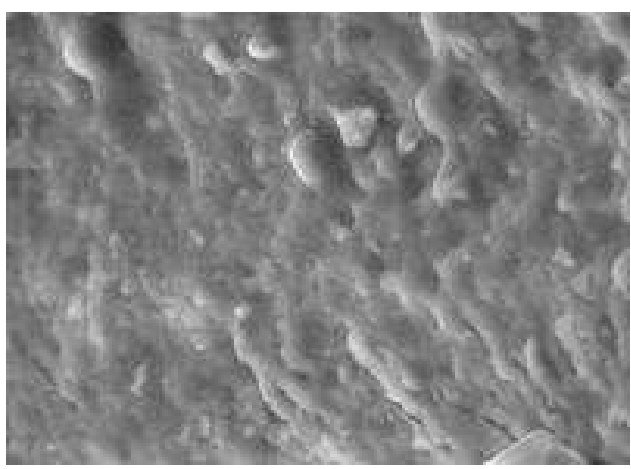

Fig VI

a. Cracked continuous bar \& lingual bar.

b. Repaired with laser welding

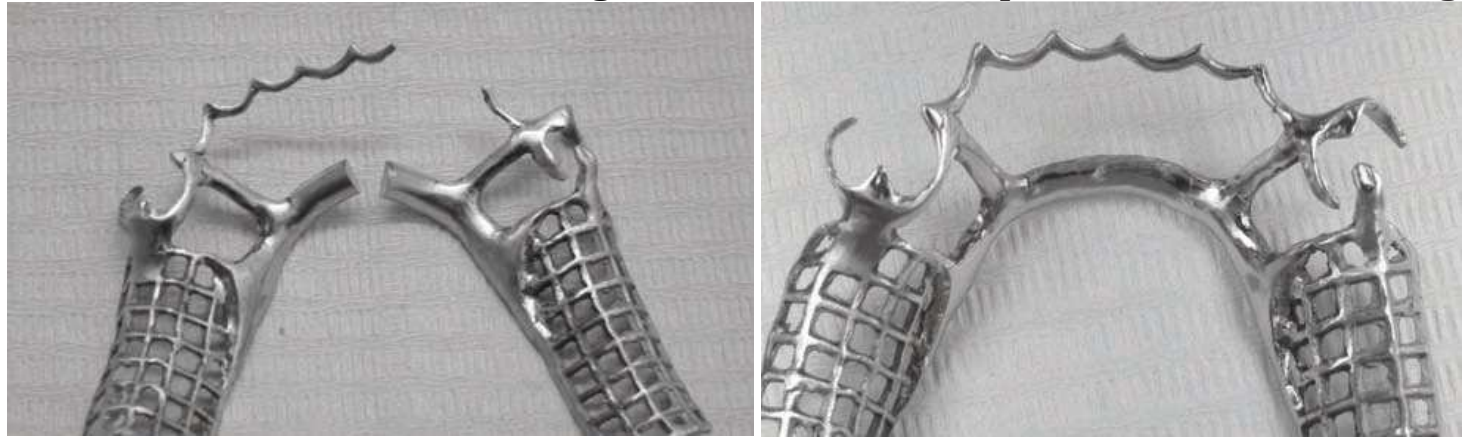

FIG V TOOTH PREPARATION WITH LASER

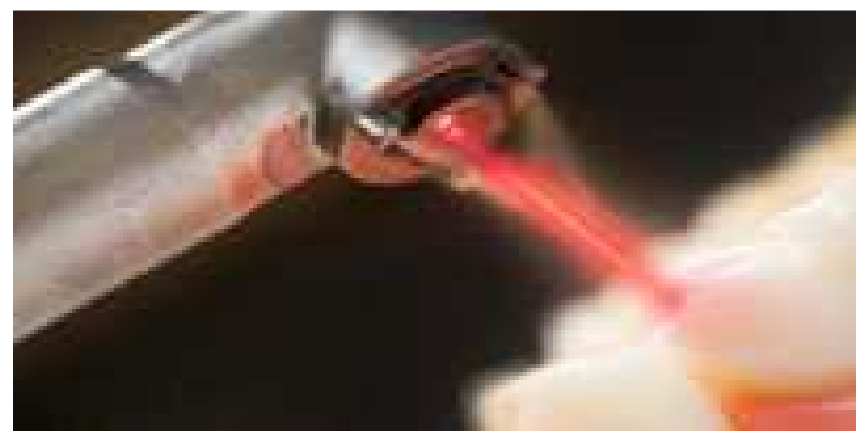

